\title{
La manzana en Los Mochis, Sinaloa: Apuntes sobre densidad habitacional, parcelación y forma de vivienda.
}

\author{
Luis Alonso de Armiño', Gonzalo Vicente-Almazán², \\ Juan Cano Forrat ${ }^{3}$ \\ ${ }^{12}$ Departamento de Urbanismo, Universidad Politécnica de Valencia, Valencia, España \\ ${ }^{3}$ INTHAB Instituto Tecnológico del Hábitat, Valencia, España. Guadalajara, México \\ E-mail: 1larmino@urb.upv.es, ${ }^{2}$ gvicente@urb.upv.es, \\ 3juancanointhab@gmail.com
}

\begin{abstract}
Resumen. Pieza unitaria del suelo discontinuo y simultáneamente unidad de agrupación de parcelas y edificios, la manzana o isla de casas es la unidad elemental que integra fisicamente la ciudad y configura, en recíproca determinación, la escala de las calles y edificios sobre los que gravita la vida urbana. Cada manzana, por lo demás, presenta una singular especificidad caracterizada por su localización en el plano de la ciudad y por la edificación que se asienta sobre su suelo.

Por otro lado, existe un consenso generalizado según el cual las ciudades y sus partes deben contener una densidad habitacional razonable para hacer posibles las actividades que cualifican la vida ciudadana. Ello implica una distribución adecuada de los edificios que contienen aquellas, distribución que tiene su correlato unitario en la configuración de las diferentes manzanas que las componen.

El desarrollo de un Taller de Arquitectura y Urbanismo realizado en la ciudad de Los Mochis (Sinaloa), nos permitió analizar algunas características de su estructura y su tejido urbano residencial: estas son, entre otras, las bajas densidades residenciales con abuso de la vivienda individual, la falta de miscibilidad entre usos residenciales y otras actividades urbanas (usos terciarios, comerciales, oficinas, etc.), la ineficiencia en términos de movilidad urbana, y la subutilización del equipamiento urbano.
\end{abstract}

Palabras clave: trazado urbano, manzana, densidad habitacional, tipología residencial.

La ciudad de Los Mochis y su marco territorial

El uso de un plan de diseño ortogonal es bastante común en un número considerable de ciudades mexicanas. En muchos casos, estas cuadrículas ortogonales corresponden a las leyes de la etapa virreinal, y su centro histórico aún puede ser identificado por la característica plaza principal, definida por la ubicación de los edificios de la Iglesia, el mercado y la autoridad civil. Sin embargo, en el noroeste de México hay una serie de ciudades y asentamientos urbanos que, aunque también cuentan con un diseño ortogonal, sus orígenes son bastante más pragmáticos y menos simbólicos $\mathrm{y}$, en muchos casos, están conectados con un impulso norteamericano de colonizar y desarrollar las tierras al sur de California.

Este es el caso de la ciudad de Los Mochis, en el estado federal de Sinaloa, México, en la cual un taller de arquitectura y urbanismo recientemente realizado nos permitió analizar algunas de las características de la estructura y la forma del tejido urbano residencial ${ }^{1}$. El objeto de las siguientes líneas es estudiar 
la flexibilidad inherente de la cuadrícula ortogonal al asumir modos y fases cambiantes del crecimiento urbano.

Con una población de 256.000 habitantes que la convierten en la segunda ciudad más grande del estado de Sinaloa, Los Mochis se encuentra en medio de una fértil llanura costera, que cubre más de 120,000 hectáreas de tierra cultivada. Si tomamos la palabra geometría en su significado etimológico como medida de la tierra, la presencia visual de la geometría en los Mochis es bastante dominante. Esto queda claro si se observa el plano o bien una fotografía aérea de Los Mochis: la tierra agrícola en particular está bien dividida y organizada mediante una cuadrícula ortogonal de gran escala, de base cuadrada y de dimensiones considerables. El plano de la ciudad de Los Mochis aparece como resultado de una subdivisión de esa cuadrícula a gran escala, como si la cuadrícula urbana se fusionara en una especie de "centuriatio" romana (G. Cataldi 2014), cuyas líneas tienen simultáneamente por objeto dividir, organizar y colonizar sin discontinuidades una gran cantidad de suelo.

Este es, de hecho, el origen de la moderna Los Mochis. Por otro lado, también parece ser el resultado por defecto de una serie de iniciativas que deberían haber merecido un destino más feliz, porque Los Mochis fue el terreno en el que se presentó una gran estrategia para establecer una colonia cooperativa llamada Pacific City en el último cuarto del siglo XIX ${ }^{2}$.

Al parecer, Los Mochis se configuró formalmente como una entidad municipal en 1903, a principios del siglo XX, pero para entonces su existencia efectiva como asentamiento urbano ya había adquirido cierta consistencia y la experiencia de los colonos se había liquidado. Las la adquisición de suelo y derechos llevada a cabo por el industrial estadounidense B.F. Johnston, fundador de la United Sugar Co (USCo) permitió ampliar la superficie de tierras cultivadas y convertir el sistema de riego en una elaborada red de canales y drenes, al parecer muy avanzada en su día (Romero Ibarra, 2003), incluido un importante ingenio azucarero. Todo ello configura un marco territorial que todavía es hoy una marca distintiva de Los Mochis.

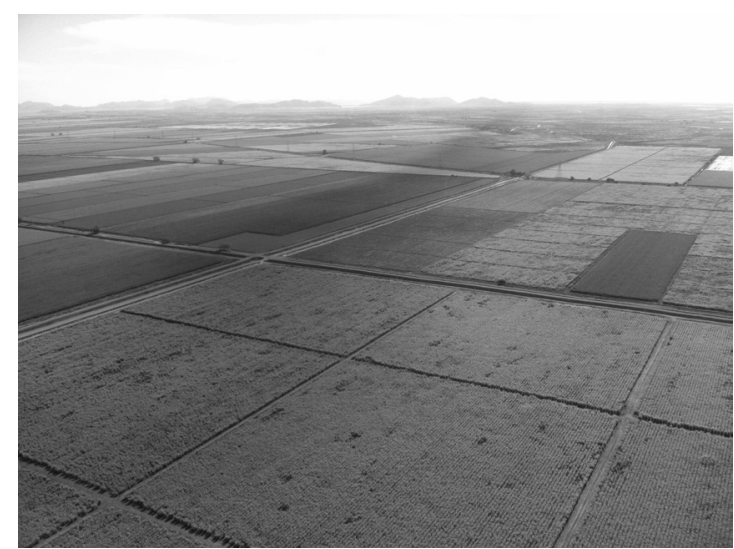

Fig. 1. Vista oblicua de los terrenos de cultivo característicos al este de la ciudad. (Fotografía de los autores).

\section{El estudio del área urbana de Los Mochis: cuadrícula mayor y cuadrícula menor.}

La red de canales y drenes forma, como ya se ha mencionado, un bastidor sustancial que abarca la ciudad y su contorno, y ha venido guiando el crecimiento de la ciudad a lo largo de los diferentes períodos desde principios del siglo XX. La característica más llamativa cuando se estudian los planos del área urbana de Los Mochis y su entorno es una cuadrícula regular de base cuadrada de gran escala, en la que cada uno de sus lados mide aproximadamente 1.000 metros y a la cual nos referiremos a ella como "cuadrícula mayor". Hemos intentado analizar cómo ha evolucionado ese original diseño en planta a lo largo de un período de casi cien años, al tiempo que se adaptaba a las cambiantes condiciones, tanto sociales como

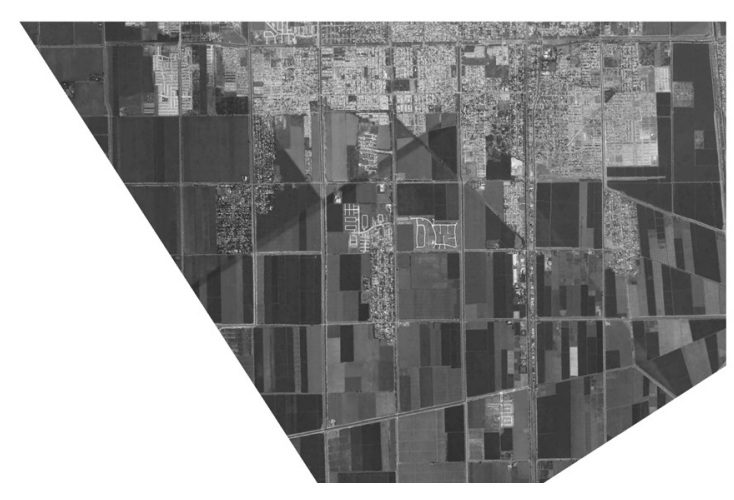

Fig. 2. La red urbana se genera a partir de la "retícula mayor", o red principal de irrigación. (Montaje sobre foto satelital de GoogleEarth elaborado por los autores) 
económicas, que iban más allá de los supuestos contemplados en sus orígenes.

Los límites del asentamiento original son difíciles de identificar, debido a la dificultad de rastrear planos y documentación gráfica durante nuestra búsqueda. Sin embargo, podemos asumir el núcleo del asentamiento original como se describe en un trabajo de investigación (Villaseñor Atwood, 2001). El área ubicada al oeste parece corresponder a lo que se denominó en la época de los colonos como Plat, mientras que el área adyacente al este corresponde a los campos de antiguos colonos que se dividieron a lo largo de las dos primeras décadas del siglo XX.

Durante los primeros años del siglo, la división de suelo de cultivo y su posterior transformación en parcelas urbanas se realizó aparentemente sin otras restricciones que las impuestas por el curso de los grandes canales, distantes entre sí un kilómetro. Los resultados no dan un orden específico ni una jerarquía clara, pero si tomamos los planos de la ciudad (documentación del IMPLAN, 2014) y nos dirigimos hacia el área adyacente al oriente del asentamiento inicial, encontramos una parte de la ciudad de tamaño considerable y totalmente organizada de acuerdo con una cuadrícula regular, más pequeña en escala, aparentemente formada por manzanas cuadradas de 100 metros por lado, separadas por calles anchas. Esta área cubre el sector nororiental de la ciudad, ubicada entre el ingenio azucarero de USCo y el promontorio llamado Cerro de la Memoria (Memorial Hill), y configura ampliamente el centro de la ciudad de hoy. Su diseño se decidió aparentemente a fines de la década de 1940 o principios de la década de 1950 y lo elegimos como ámbito de estudio como la parte más coherente de la trama urbana. Por cierto, esta misma área constituye también el centro de la ciudad, con la mayor concentración

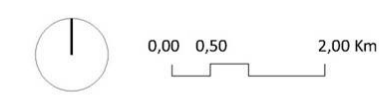

\section{Los Mochis}

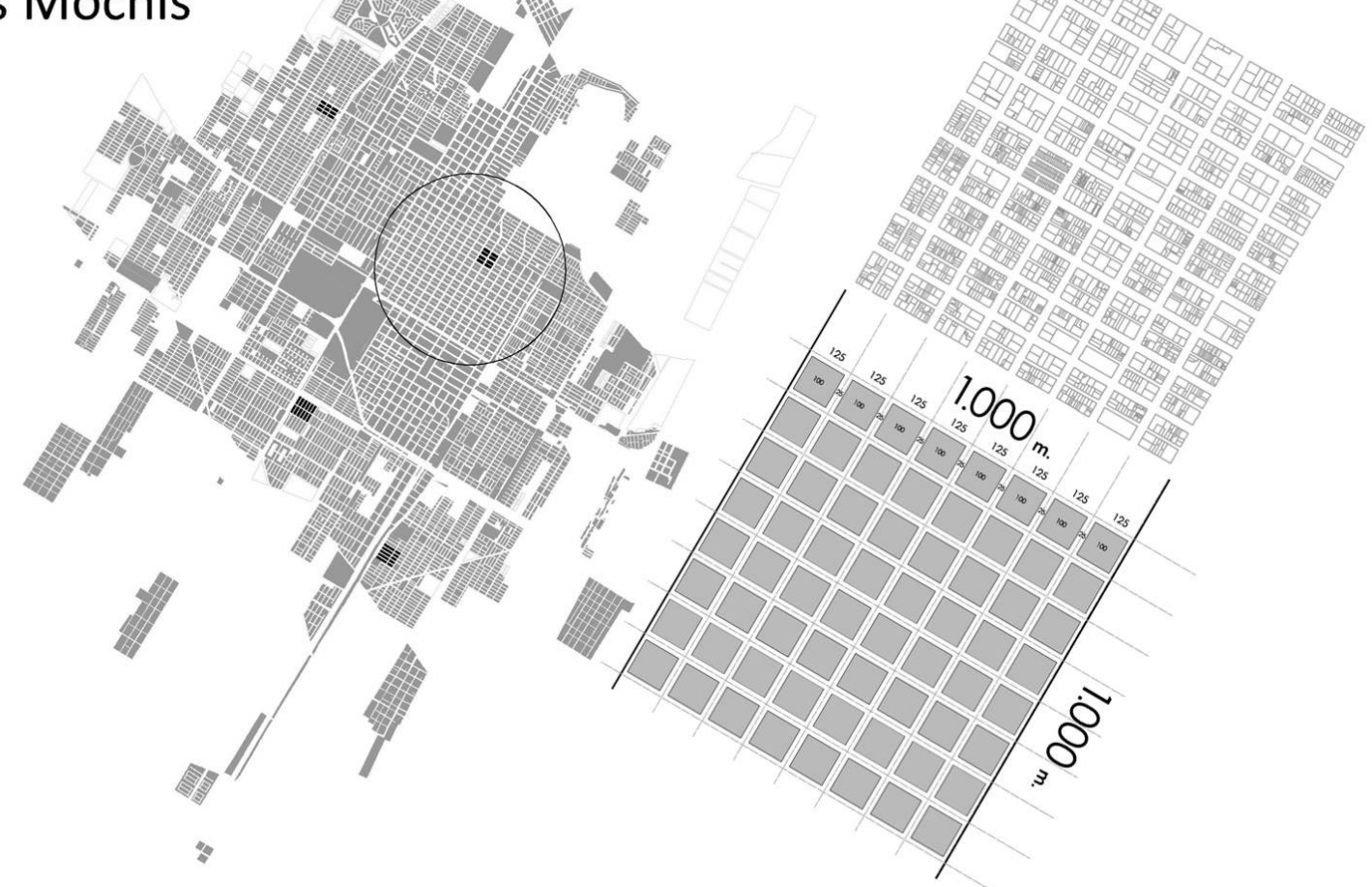

Fig. 3. Plano de la ciudad de Los Mochis. El círculo marca el centro urbano interior donde se localiza el área de estudio. Los bloques marcados en negro son áreas residenciales referidas como Zonas $\mathrm{A}, \mathrm{B}, \mathrm{C}$ y $\mathrm{D}$ en el texto y las Figuras no 6 y 7. (Plano elaborado por los autores) 
de servicios urbanos, así como la imagen y la atmósfera asociada a la centralidad urbana, en términos de actividad en la calle.

La manzana como unidad básica de la cuadrícula en la generación del tejido urbano.

El cuadrilátero delineado anteriormente tiene límites que se extienden en dirección noreste-suroeste a lo largo del bulevar Antonio Rosales y el General Macario Gaxiola, cuya extensión conecta la ciudad con el puerto de Topolobampo. En sentido transversal los límites son las avenidas Independencia y 10 de Mayo. Estos cuatro ejes también delimitan en gran medida el centro de la ciudad y forman un cuadrado que mide dos kilómetros de lado, que comprende 4 cuadrados de $1.000 \times 1.000$ $\mathrm{m}$, correspondientes a la "cuadrícula mayor" derivada de la red de irrigación. Tomamos uno de esos cuadrados como base para analizar la geometría del tejido urbano y observamos que se subdivide de acuerdo con una retícula ortogonal regular de $125 \mathrm{~m}$, paralela a los lados del cuadrado entre ejes. Nos referiremos a esta cuadrícula secundaria como "cuadrícula menor". Al convertir los ejes en calles de $25 \mathrm{~m}$ de ancho, obtenemos ocho subunidades, cada una de las cuales es el generador del elemento base: la manzana de 100x100 metros

\section{La evolución del tejido urbano a través del proceso de división de la trama.}

La subdivisión de la manzana: jerarquía espacial primaria.

Las referidas manzanas de 100x100 m están subdivididas a su vez por una calle interna o callejón de servicio de $10 \mathrm{~m}$ de ancho. Esta operación transforma la manzana previamente cuadrada en dos manzanas rectangulares que miden $45 \times 100 \mathrm{~m}$, originando dos bandas paralelas de parcelas (y sus edificaciones).

Con la apertura de estas calles secundarias de servicio, la jerarquización del sistema de trazado viario queda fijada en dos niveles, a saber, las calles principales y los callejones traseros. Asimismo, las 'bandas' de parcelas de 100x45 m que forman los lados "largos" de la manzana quedan definidas como el soporte geométrico en el que se llevará a cabo la subdivisión del suelo: uno frente a una calle principal y otro frente a la calle o callejón secundario.

Esta disposición en planta da origen a una suerte de jerarquización primaria: las parcelas tienen una fachada frontal recayente a la red de calles principales, mientras que también tiene una fachada especializada en la parte posterior, abierta a la conexión con los servicios urbanos. Esta doble relación caracteriza y condiciona la evolución urbana.

La orientación de las parcelas.

Dentro del área de estudio, los manzanas que hemos definido como típicas se sistematizan según la dirección noroeste-sureste, es decir, a lo largo de la línea marcada por las calles de atrás o de servicio, y en ángulo recto con respecto a los ejes de las calles principales, a excepción de las cinco manzanas que dan frente al boulevard Antonio Rosales. Esta disposición es lógica si tomamos en cuenta la naturaleza de los principales ejes noreste-sudoeste como colectores de tráfico, y red y alcantarillado, un esquema en el que la posición perpendicular de los callejones traseros como distribuidores de servicios corresponde a la opción más eficiente. Las cinco manzanas que forman la excepción a esta regla se encuentran al lado del ingenio azucarero de USCo uno de los ejes generadores $\mathrm{y}$, muy probablemente, son el resultado de un fallido intento inicial de crecimiento de la ciudad que luego fue redirigido en el sentido apuntado.

\section{Algunas hipótesis sobre la evolución de los procesos de subdivisión de la trama.}

La situación actual muestra una gran diversidad de formas y tamaños en la subdivisión de parcelas. Sin embargo, creemos poder adivinar procesos repetitivos que remiten a una hipótesis acerca de la evolución de una estructura doméstica de tamaño unitario grande a otra de tamaño más pequeño. Las dimensiones y la disposición de las parcelas sugieren que, inicialmente, la estructura parcelaria explotaba las ventajas de la función 


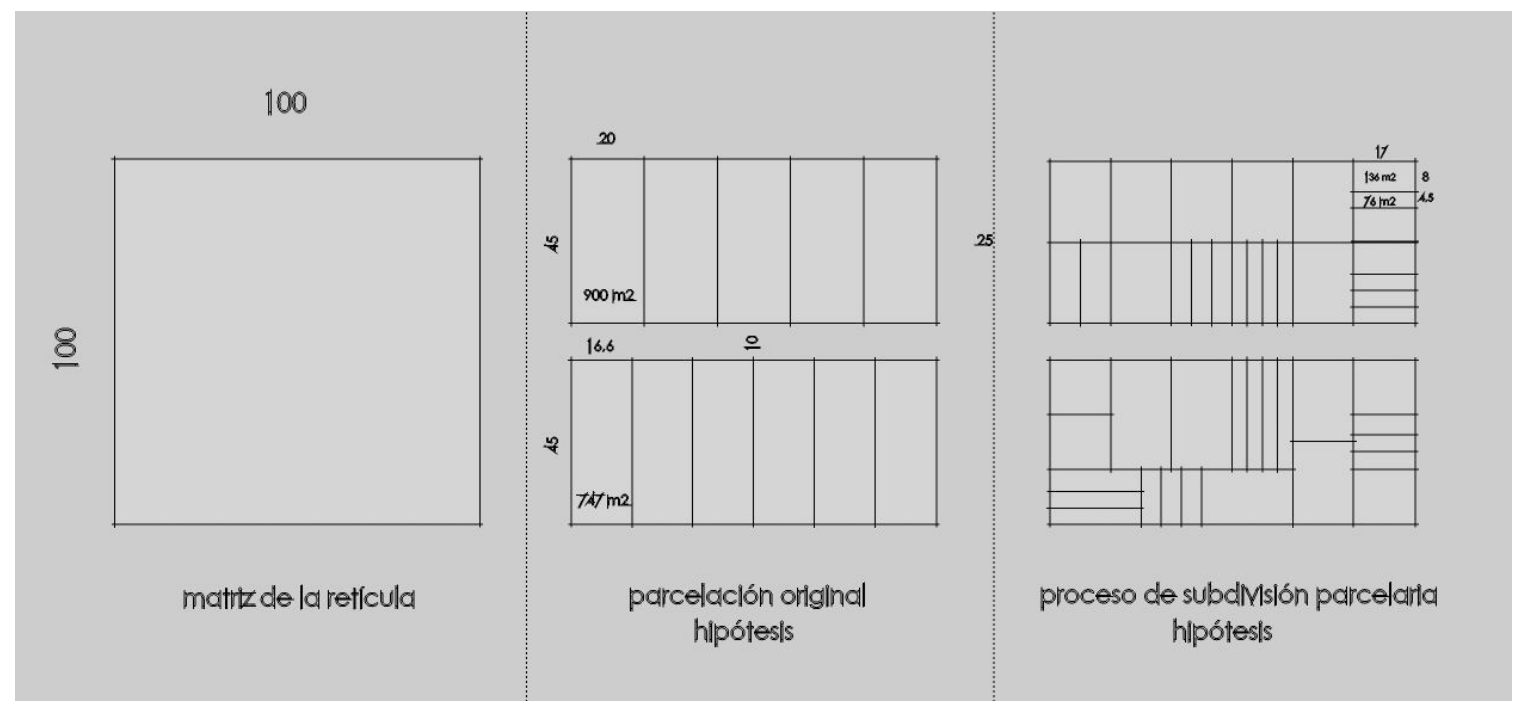

Fig. 4. División del suelo: el módulo de manzana de 100x100 m. La figura muestra una evolución hipotética de la división de suelo en el área central de la ciudad, desde los tipos de parcelas residenciales iniciales hasta la subsiguiente división / agrupación de parcelas como medio para adaptar el tejido urbano a las necesidades cambiantes impuestas por los usos terciarios, el tejido urbano que responde a su condición de centralidad urbana. Izquierda, unidad dimensional principal; centro, hipotética división original en parcela; derecha, subsiguientes subdivisiones hechas para satisfacer demandas del mercado inmobiliario especializado. (Plano elaborado por los autores)

dual proporcionada por la jerarquía de calles, y las parcelas de edificios se extendían desde la calle principal hasta el callejón o vía de servicio posterior. Queda por definir el número de lotes por banda $\mathrm{y}$, si tiene en cuenta cantidades estadísticas, asumimos una subdivisión típica de cada frente de $100 \mathrm{~m}$ en 5 unidades de 20 $\mathrm{m}$ o, alternativamente, 6 unidades de $16,60 \mathrm{~m}$, correspondientes respectivamente a parcelas de superficie de $900 \mathrm{~m} 2$ o $750 \mathrm{~m} 2$.

Optar por este formato podría haber sido dictado por la naturaleza de los tipos de vivienda preferidos en el período inicial, es decir, grandes parcelas recayentes a las calles principales $(25$ $\mathrm{m}$ de ancho) y con la parte trasera al callejón de servicio (10 $\mathrm{m}$ de ancho). En términos de edificaciones esto correspondería a un tipo de casa familiar sustantiva, por lo general exenta, compuesta por pabellones articulados, con grandes patios interiores y jardines abiertos, e incluso pequeños almacenes o talleres, como podría corresponder a los ideales de los colonos, quienes eran, después de todo, los previsibles adquirentes.

La calle trasera o el callejón de servicio cumplieron plenamente su propósito al utilizarse para instalar las conducciones de electricidad, alcantarillado y agua, como se puede ver hoy.

El estado actual del tejido urbano, después de casi cien años, es el resultado de adaptar la geometría original a los requisitos operativos que se han ido presentando a lo largo del tiempo. Con la progresiva extensión de la tierra de cultivo y la llegada de un número creciente de población laboral, la demanda de vivienda debió cambiar: las unidades familiares más modestas requerían viviendas más baratas y reducidas, lo que debió fomentar la subdivisión de las parcelas originales. Esta subdivisión en unidades más pequeñas también trajo consigo un proceso de densificación habitacional, al insertar a más habitantes y actividades por unidad de superficie.

La subdivisión más significativa se produce cuando las bandas de parcelas con fachada tanto a las calles principales como a las secundarias, se dividieron a lo largo de una directriz longitudinal, paralela al frente de calle, generando así una doble línea de parcelas edificables, yuxtapuestas espalda contra espalda, una de ellas con frente a la calle principal y la otra con fachada al callejón posterior. Esta subdivisión implicaba la pérdida de las ventajas de las que disfrutaba el sistema de parcelas anterior, ofreciendo cada parcela (y 
edificio) con accesos dobles y jerarquizados, sometidas así a los requisitos de un mercado inmobiliario más complejo y variado.

Dirigido a una escala urbana más amplia, este proceso reasignó de algún modo las funciones de la red de calles. El sistema de calles secundarias asumía ahora funciones especializadas, relacionadas con usos específicos a lo ancho del tejido urbano, y abarcaba desde pequeños hogares hasta una variedad de usos terciarios como el mercado de productos del barrio, almacenes, estacionamiento, talleres y otros usos complementarios con los principales locales comerciales situados en los ejes principales. En algunas zonas, este uso especializado de venta minorista indujo una alta segmentación de las parcelas, con fachadas mínimas que se acercan a los 4,00 metros de ancho (Ver Fig. 3).

Un segundo recurso en la diversificación del tejido urbano fue el uso de la subdivisión de parcelas con reconocimiento de la primacía de la calle de dirección noreste-suroeste sobre su opuesto (noroeste-sureste). En la mayoría de los casos, podemos encontrar que, en los extremos de la manzana, la subdivisión se lleva a cabo girando $90^{\circ}$ las nuevas parcelas, de modo que dan fachada a estos ejes, claro signo de un mayor valor atribuido a ese frente, aun cuando ello implique generar anchos de fachada (y parcelas) más reducidas de todo el tejido.

La subdivisión no es, sin embargo, la única forma posible de adaptar las parcelas a nuevas actividades: también encontramos su opuesto, los casos de agrupación o agregación de parcelas, para satisfacer la demanda de nuevos usos urbanos más modernos, recientemente incorporados a las áreas centrales de la ciudad, como grandes almacenes, centros de convenciones, hoteles, e incluso estaciones de servicio. En resumen, una gama variada de tamaños de edificios y parcelas que se adaptan a la flexibilidad tipológica propia de las retículas hipodámicas.

\section{Distribución de densidad residencial en el plano de la ciudad.}

Si trazamos una línea imaginaria desde el ingenio azucarero de la USCo hasta el Cerro

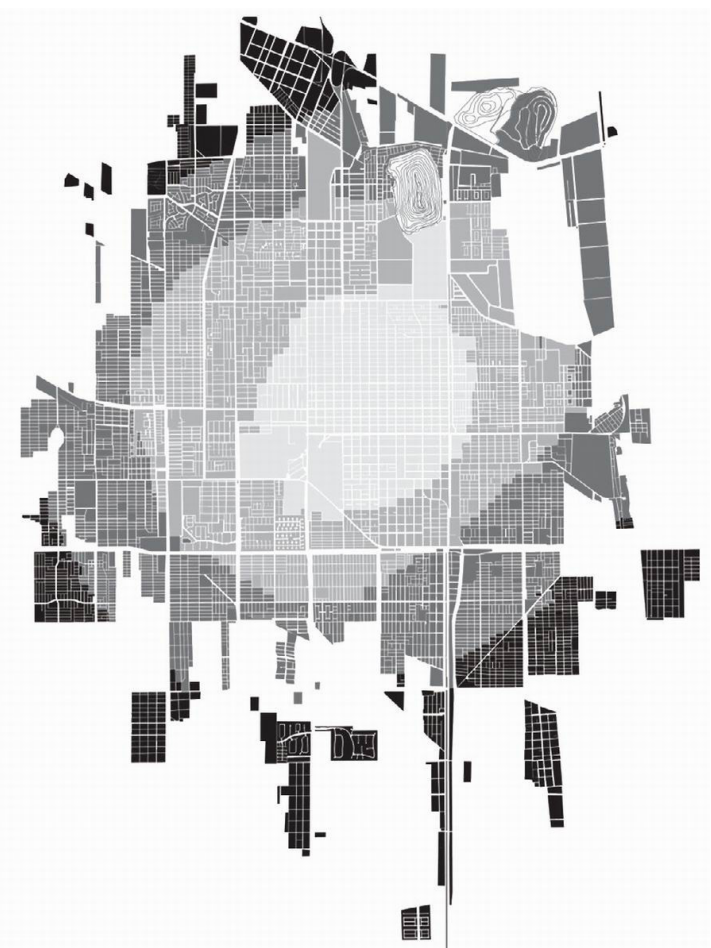

Fig. 5. Gradiente de densidad residencial. Representación esquemática del Gradiente de densidad residencial, mostrando los resultados de los fenómenos de "terciarización" en Los Mochis. Los usos comerciales y la mayoría de los equipos urbanos se han concentrado progresivamente en el "centro de la ciudad". El tejido residencial es expulsado a la periferia. (Plano elaborado por los autores)

de la Memoria y desde su centro se dibujan una serie de círculos concéntricos se obtendría una imagen aproximada del gradiente de densidad residencial dentro del área de estudio: la densidad residencial disminuye desde los anillos exteriores hasta ser casi inexistente en el centro de la ciudad más antigua. Aparece como un ejemplo de segregación entre la residencia y los usos terciarios, un fenómeno bien conocido que se asume frecuentemente en las ciudades de América del Norte: la parte central del círculo se halla prácticamente deshabitada.

La forma de las parcelas se adapta a esta situación y podemos encontrar la mayor variedad en correspondencia con el comercio minorista y la actividad comercial en áreas centrales, la concentración de parcelas pequeñas en mercados secundarios especializados y pequeños locales comerciales contiguos a parcelas más grandes, resultantes de variadas agregaciones, que albergan comercios de 
gran superficie. Cuando nos alejamos de esta hipotética área central y llegamos a localizaciones periféricas, la regularidad se convierte paso a paso en la norma, y las manzanas principalmente residenciales imponen parcelas y tipos de edificios más estables.

\section{Las variantes parcelarias del tejido residencial.}

Como se ilustra en la Figura 5, la mayoría de las partes de tejido residencial tienen una situación periférica con respecto al centro de la ciudad. Parece apropiado analizar su estructura para compararla con el área de la ciudad central en la que hemos encontrado usos residenciales casi inexistentes. Con respecto a la estructura general de la ciudad, la cuadrícula principal de $1.000 \mathrm{~m}$, derivada de la matriz agrícola, permanece, pero la subsiguiente cuadrícula de $100 \times 100 \mathrm{~m}$, que aparece tan claramente en el área central que hemos descrito, parece desvanecerse en subdivisiones de origen más aleatorio.

Para tener una vista más cercana de los diferentes tejidos residenciales que constituyen las áreas urbanas externas, elegimos cuatro ubicaciones en cada una de las esquinas del anillo y delimitamos en cada área el equivalente a una serie de cuatro manzanas de la cuadrícula anterior, de 100x100 m. La selección del tamaño parece suficientemente representativa como muestras cuyos resultados pueden extrapolarse a toda la ciudad. En cada área, determinamos el tamaño de manzana típico, el ancho de las calles, junto con el sistema de parcelas y tipos de edificios, con los siguientes resultados.

\section{Zona A:}

Estudiamos un grupo de 12 manzanas delimitadas por las calles Jiquilpan, Dren Juárez, Quintana Roo y Veracruz Norte. El grupo se sitúa en vértice noroccidental del ámbito central objeto de estudio ciudad. La mayoría de las manzanas están orientadas en una dirección perpendicular al curso aproximadamente norte-sur seguido por los canales. Las manzanas tienen una dimensión de $80 \times 40 \mathrm{~m}$ y están constituidos por una
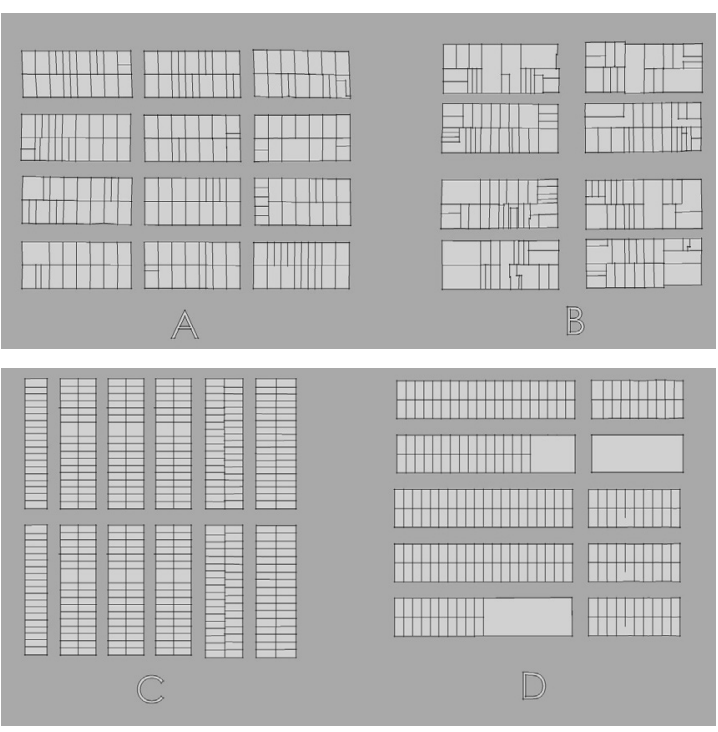

Fig. 6. (arriba) Estructura de la parcelación residencial. Zonas A y B

Zona A: (Jiquilpan - Dren Juarez - Quintana Roo VeracruzNorte). Dimensiones de manzana: 82 x $40 \mathrm{~m}$. Calles de acceso local $11 \mathrm{~m}$. - Distribuidores locales $15 \mathrm{~m}$. Dimensiones parcela tipo: $11 \times 20 \mathrm{~m}=220 \mathrm{~m} 2$ y $5,5 \times 20=110 \mathrm{~m} 2$. Edificio característico : Vivienda unifamiliar adosada

Zona B: (Heriberto Valdez -Constitución - Serapio Redón - Emiliano Zapata). Dimensiones de manzana: $100 \times$ 100. Calles de acceso local. $25 \mathrm{~m}$. - Callejón trasero de servicio $10 \mathrm{~m}$. Dimensiones parcela tipo: $8 \times 22,5=180$ m2. Edificio característico : Vivienda unifamiliar aislada o exenta

Figura 7. (abajo) Estructura de la parcelación residencial. Zonas C y D

Zona C: (Agustina Ramirez - Justo Sierra - Mariano Escobedo - Antonio Rosales). Dimensiones de manzana: 118 x 32. Calles de acceso local. $11 \mathrm{~m}$. Distribuidores locales $15 \mathrm{~m}$. Dimensiones parcela tipo: 6,5 x 16 m = 104 m2. Edificio característico : Vivienda unifamiliar adosada

Zona D: (Huinolo -Prado Horizonte -Ciruelos Macario Gaixola). Dimensiones de manzana: 82 x 34 . Calles de acceso local y Distribuidores locales: 15 m. Dimensiones parcela tipo: $8 \times 16=128 \mathrm{~m} 2$. Edificio característico : Vivienda unifamiliar aislada o exenta (Esquemas elaborados por los autores)

doble banda de parcelas bastante regulares, alineadas espalda con espalda. La agrupación de manzanas tiene una red de calles interior hecha de dos tipos de calles, las que hacen la fachada longitudinal y dan acceso a casas son de $11 \mathrm{~m}$ de ancho, mientras que las calles que forman los extremos de los manzanas y que actúan como colector de tráfico local tienen 15 
$m$ de ancho. Existen dos tipos de parcelas: las de $11 \times 20 \mathrm{~m}(220 \mathrm{~m} 2)$ y su subdivisión 'natural' de $5,50 \times 20 \mathrm{~m}(110 \mathrm{~m} 2)$.

\section{Zona B:}

Estudiamos un grupo de 8 manzanas ubicadas entre las calles Heriberto Valdez, Constitución, Serapio Rendón y Emiliano Zapata. El grupo está ubicado en el vértice nororiental del ámbito central objeto de estudio y mantiene la misma estructura urbana pero con una prevalencia absoluta residencial. En este caso la manzanatipo es de 100x100 m, manteniendo el sistema jerárquico de calles de 25 y $10 \mathrm{~m}$ de ancho, con líneas de trazado de 100x45 metros. Aunque hay una variedad considerable, asumimos que la parcela típica es una unidad de $8 \times 22,50 \mathrm{~m}$, cubriendo un área de $180 \mathrm{~m} 2$.

\section{Zona C:}

Estudiamos un grupo de 12 manzanas delimitado por las calles Agustina Ramírez, Justo Sierra, Mariano Escobedo y Antonio Rosales. Se halla situado en el vértice suroccidental del ámbito central objeto de estudio, y las parcelas se orientan en dirección paralela a los canales, con vías de acceso a parcelas de $11 \mathrm{~m}$ de ancho y calles que forman los extremos de las manzanas y que actúan como colectores de tráfico local de $15 \mathrm{~m}$. de ancho. Las medidas de manzana resultantes son $118 \times 32 \mathrm{~m}$. La parcela típica es de 6,50x16 $\mathrm{m}$, con una superficie de $104 \mathrm{~m} 2$.

\section{Zona D:}

Estudiamos un grupo de 10 manzanas delimitado por las calles Huinolo, Prado Horizonte, Ciruelos y Macario Gaxiola. Se halla situado en el vértice suroriental del ámbito central objeto de estudio, junto a la carretera de Topolobampo, con las parcelas orientadas en una dirección perpendicular al curso seguido por los canales, que es aproximadamente noreste-suroeste. Las medidas de manzana resultantes son de $82 \times 34 \mathrm{~m}$, todas las calles tienen $15 \mathrm{~m}$ de ancho. La parcela típica es de $8 \times 16 \mathrm{~m}$, con una superficie de $128 \mathrm{~m} 2$.

Con la excepción de la Zona B, las otras

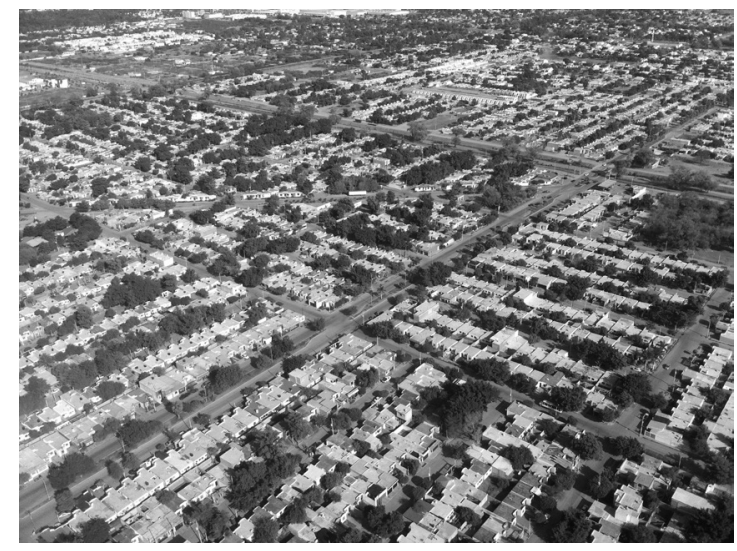

Fig. 8. Tejido residencial formado por viviendas unifamiliares adosadas. Vista aérea de tejido residencial en Zona $C$. La fotografía muestra la intersección de Bulevar Pedro Anaya y Diagonal Sur. (Fotografía de los autores)

tres Zonas comparten un solo tipo de edificio: la casa unifamiliar adosada de una sola planta, excepcionalmente de dos, que corresponde al desarrollo típico a gran escala de las agrupaciones financiadas a través del Infonavit, con variaciones mínimas en el tamaño de la parcela, la huella edificada y el programa habitacional, es decir, casas adosadas con 2-3 dormitorios, de 60 a $100 \mathrm{~m} 2$ en parcelas que van de 100 a $150 \mathrm{~m} 2$.

El orden de la descripción de las zonas coincide con la secuencia temporal de la construcción efectiva de cada una, de modo que se puede percibir la gradual disminución en la calidad de los estándares habitacionales y del espacio público. La forma y el tamaño de las manzanas y la lógica de su agrupación limitan progresivamente la versatilidad del tejido urbano y, al mismo tiempo, empobrecen la interacción urbana y la miscibilidad de los usos, particularmente cuando se comparan con el área central. Las manzanas se vuelven mono-funcionales, incapaces de soportar nada más que sus (muy) modestas construcciones residenciales.

\section{Algunas conclusiones provisionales}

En cuanto a los orígenes del diseño de retícula cuadrada en el caso de Los Mochis, queda claro que algunas ciudades de México cuyo plano responde a una cuadrícula ortogonal regular no deriva con las leyes coloniales españolas, 
con un núcleo simbólico central; ni siquiera de acuerdo con planes derivados de la reflexión técnica. Los Mochis parece ser un caso singular, en el que, pese a su improbabilidad, ha sido la infraestructura de riego quien ha proporcionado las líneas maestras que guían su desarrollo tanto geométrica como materialmente desde hace casi un siglo.

Durante muchas décadas, hasta la década de 1960 , todo indica que la mayoría de los canales y drenes formaron una suerte de red que coexistía en superficie con las principales arterias de tráfico de la ciudad. Posteriormente, casi todos ellos fueron dispuestos en canalizaciones enterradas y desaparecieron del entorno urbano. Pero en la actualidad existe una tendencia creciente hacia su recuperación en superficie y su incorporación a una concepción renovada y paisajística de bulevares y avenidas. Si se consiguiera crear una escena urbana nueva, en la que las arterias principales pongan en valor las vías de agua integrándolas en una suerte de parques lineales, la ciudad no haría sino rendir merecido tributo al hecho infrecuente de haber sido desarrollada siguiendo un sistema de canales de irrigación.

Por otro lado, hemos intentado mostrar que el plan de área central de la ciudad, dividiendo la unidad de "retícula mayor" en ocho partes, por lo que la creación de la manzana modular de 100x100 m ha sido, con mucho, el episodio más exitoso: establece un modelo compacto y moderado de uso del suelo, que proporciona versatilidad en términos de organización de parcelas (y edificios), junto con una red de calles adecuada, y una base para la identidad local. Esta estructura tampoco es ajena al carácter del área central, hoy convertida en el centro urbano con todos sus atributos de vibrante actividad e interacción personal. Perversamente, ha sido su naturaleza y ubicación únicas en Los Mochis, junto con la cultura predominante hacia la vivienda unifamiliar y el uso del automóvil, la que ha propiciado su declive como un tejido urbano totalmente integrado. Hoy en día, tiendas y oficinas cubren la mayor parte del área edificada, impidiendo la introducción de un mercado de vivienda creíble. Esto explica el típico esquema de "donut" que se muestra al mapear la distribución de la densidad de viviendas, con un hueco que marca el centro de la ciudad.

La contrapartida de lo descrito en las líneas anteriores se puede observar en los desarrollos de vivienda que cubren hoy una gran extensión de la periferia de Los Mochis. Grandes conjuntos de viviendas compuestos por casas adosadas mínimas, que además, añaden a su banalidad índices bajos de densidad habitacional (alrededor de 30 viviendas por hectárea), haciendo casi imposible cualquier programa de inversión adecuado para aumentar la provisión de servicios y equipamientos urbanos. El abuso de la vivienda unifamiliar implica la dificultad para incorporar otros tipos de edificios que permitan cierto grado de miscibilidad con otras actividades urbanas (usos terciarios, comerciales, oficinas, etc.). Las bajas densidades también significan ineficiencia en términos de movilidad urbana, falta de "masa crítica" de población residente en cuanto a las líneas de transporte público rentables, mientras que induce la subutilización de la mayoría de los elementos del equipamiento urbano público.

Las ciudades sostenibles necesitan eficiencia en su relación densidad y ocupación de suelo. Una mayor densidad residencial (es decir, viviendas urbanas a partir de la primera planta) proporciona un uso eficiente del suelo, mayor rentabilidad en la prestación de servicios y el desarrollo de sistemas de transporte eficaces y energéticamente eficientes, al tiempo que minimiza la "huella" urbana. Las autoridades mexicanas parecen ser conscientes de que la expansión de la vivienda, incluso como suelo urbano periférico, como es el caso de Los Mochis, debe abordarse a través de la densificación o reutilización de tierras previamente desarrolladas, suelos infrautilizados o desocupados, como se recomienda en las ciudades europeas, incluso si la densificación se extiende a la conversión y reutilización de edificios existentes. Los Mochis deben corregir la decadencia de su centro urbano actual transformando este en un tejido compacto, en el que la reintroducción del desarrollo de viviendas y la mejora de la calidad ambiental deberían ser las líneas maestras. Parece ser todo un reto dada la potente cultura de la vivienda unifamiliar que parece existir en el noroeste de México, pero en todo caso es un reto ineludible. 
Notas

1 El presente texto desarrolla algunas ideas que fueron avanzadas por los autores en la ISUF 2014 Conference, desarrollada en Oporto en julio de 2014.

2 La idea detrás de esta iniciativa correspondió al visionario estadounidense Albert Kinsey Owen, quien había visitado la región de Los Mochis y estaba al tanto de las convenientes condiciones naturales de las tierras y su estratégica localización junto al mar. Albert K. Owen también fue un ardiente reformador, predicando las ventajas de una utopía de orden social llamada "Cooperación Integral”. Imaginó una colonia ideal llamada Pacific City, apoyada en la creación de un puerto de aguas profundas en la bahía de Topolobampo, en la costa de Mochis, junto con la construcción de una línea de ferrocarril a Galveston, Texas, que uniría el puerto con la red ferroviaria de los Estados Unidos, ofreciendo un puerto de cabecera en el Pacífico para el comercio de los Estados Unidos con Asia mucho antes de la apertura del Canal de Panamá. El comercio, la producción de tierra y la industria florecerían en un sitio ideal. A estos efectos, bajo los auspicios de A.K. Owen, se creó en 1883 una empresa de capital social denominada Credit Foncier Company (más tarde Credit Foncier de Sinaloa Co.). Se obtuvieron los fondos para la financiación y se proyectaron los planos para Pacific City y el trazado de la línea del ferrocarril, Más de mil futuros colonos fueron reclutados e instalados en el área de Los Mochis. Pero a partir de ese momento, todo salió al revés (Ortega Noriega, 2003) por diversas razones que exceden de los objetivos de este breve texto: Conflictos y divisiones entre los colonos, y sucesivas quiebras financieras terminaron con los grandiosos planes para establecer Pacific City (Lovell, 1878) y dejando simplemente una tierra colonizada dedicada a la cosecha de caña de azúcar, hecha viable por la apertura de un canal de irrigación (el canal de Taxtes o Tastes) que conduce las aguas del vecino Río Fuerte.

\section{Referencias}

John W. Lovell (1878) "A co-operative city and the Credit Foncier of Sinaloa", (Lovell, J.W Publishing, New York).

Giancarlo Cataldi et al., "Territory and urban planning in Northern Sinaloa: Geometric rationalization of the land structure in the municipalities of Ahome and Guasave" en Oliveira V. et al. (eds.) (2014) Our common future in Urban Morphology Vol.2. FEUP, Oporto; 53-65,

Fogarty R. S. (2003)"All things new: American communes and utopian movements 1860 1914" (Lexington Books, Maryland), 121134.

Romero Ibarra, Ma Eugenia (2003) “Azúcar y empresa: La United Sugar Companies S.A.,1890-1950" en Trujillo, M. et al, "Formación empresarial, fomento industrial y compañías agrícolas en el México del siglo XIX”, (CIESAS, México), 357-365.

Romero Ibarra, Ma Eugenia (2003) "Benjamin F. Johnston, un empresario norteamericano en el norte de Sinaloa a finales del siglo XIX y principios del XX" en Meyer, M. et al. "Los inmigrantes en el mundo de los negocios, siglos XIX y XX”, (Plaza y Vldés, México), 157-167.

Sergio Ortega Noriega (2003) "El Edén subvertido: La colonización de Topolobampo 1886-1896", (siglo XXI, México), 87-110.

Villaseñor Atwood, Arturo (2001) "Orígenes históricos de los Mochis", (Universidad de Occidente, México), 24-42.

IMPLAN (Instituto de planeación municipal), documentación proporcionada por el Consejo Municipal de Desarrollo Urbano y ecología del municipio de Ahome, Ayuntamiento de Los Mochis, incluyendo el "Plan Director de Desarrollo Urbano de la ciudad de Los Mochis 2006-2020". Consultado en Enero de 2016 